\title{
Influence of physical seed treatment on seed quality improvement in black gram (Vigna mungo L.)
}

\section{R. Anbarasan* and P. Srimathi}

Department of Seed Science and Technology, Tamil Nadu Agricultural University, Coimbatore- 641003 (Tamil Nadu), INDIA

*Corresponding author. E-mail: anbu107@yahoo.com

Received: March 3, 2015; Revised received: September 19, 2015; Accepted: January 18, 2016

Abstract: Pelleting is a physical pre-sowing seed management technique, in which seeds are enclosed with biopromotive substances to improve the field stand. To evaluate the efficacy of plant herbal powders for seed pelleting, studies were initiated with blackgram cv. ADT 3, in which seeds were pelleted with the leaf powders of noni (Morinda citrifolia) and basil (Ocimum sanctum) and fruit powder of gallnut (Terminalia chebula) @ $200 \mathrm{~g} \mathrm{~kg}^{-1}$ of seed using Carboxy methyl cellulose @ $200 \mathrm{ml}$ per kilogram of seed as an adhesive. The results revealed that seeds pelleted with the leaf powders of either basil improved the seed germination by $6 \%$ and seedling vigour (23\%), seedling length $(9 \%)$ and seedling dry weight $(5 \%)$. In raised bed nursery, the seeds pelleted with basil leaf powder @ $200 \mathrm{~g}$ $\mathrm{kg}^{-1}$ of seed recorded improved field emergence $(7 \%)$ with higher chlorophyll index $(30 \%)$ and nodule number $(28 \%)$ highlighting the efficacy of the treatment. While, the seeds pelleted with gallnut fruit powder recorded lowest germination, vigour and field emergence which is significantly lesser than control. The delayed emergence, germination and vigour was due to the increase in hardiness of gallnut powder pelleted seed. Thus, the seeds treated with basil leaf powder @ $200 \mathrm{~g} \mathrm{~kg}^{-1}$ using carboxy methyl cellulose @ $200 \mathrm{ml}$ per kilogram of seed as an adhesive, enhanced seed germination, vigour, seedling length and dry weight.

Keywords: Field Emergence, Herbal Powders, Seed Pelleting, Seedling Quality

\section{INTRODUCTION}

Blackgram (Vigna mungo L.) is one of the important pulse crop of India having 26 per cent protein, 57 per cent carbohydrate, 1.2 per cent fat and with good source of phosphoric acid, calcium and vitamins like thiamine $\left(B_{1}\right)$, riboflavin $\left(B_{2}\right)$ and niacin $\left(B_{3}\right)$. The major constraint in pulse production is low productivity as they are being grown in sub marginal soils which are having low fertility and with least care. The productivity could be improved by adoption of proper management techniques including seed. Seed pelleting is a pre sowing physical seed management technique, in which growth promotive substances or any needy substances with protective, nutritive and invigourative function are applied on the seed to enhance the seed-soil relationship at the rhizosphere region (Srimathi et al., 2013) and there by enhance the initial seedling growth and productivity. Research on pelleting also highlighted the efficacy of organic herbal powder as filler material with better invigourative efficacy (Shashibhaskar et al., 2012). In organic farming, development of ecofriendly production techniques using natural product is much warranted particularly in blackgram which has economic value as food product. Among the various medicinal plants, leaves of noni (Morinda citrifolia), basil (Ocimum sanctum) and fruits of gallnut (Terminalia chebula) plants have wider protective and invigourative influence due to presence of antioxidant, essential minerals, proteins, amino acids and vitamins (Kadian and Parle, 2012; Suryaprakash et al., 2012 and Chandra and Sagar, 2013). Hence, an attempt was made to evaluate the suitability of the leaf powders of basil, noni and fruit powder of gallnut as filler material for seed pelleting in blackgram cv. ADT 3 to improve the field stand and seedling vigour of at Dept. of Seed Science and Technology, Tamil Nadu Agricultural University, Coimbatore $\left(11^{\circ} 1^{\prime} 6^{\prime \prime} \mathrm{N}, 76^{\circ} 58^{\prime} 21^{\prime \prime} \mathrm{E}\right)$.

\section{MATERIALS AND METHODS}

Breeder seeds of blackgram cv. ADT 3 obtained from Tamil Nadu Rice Research Institute, Aduthurai were graded to obtain uniformity in size. Fresh matured leaves of noni (M. citrifolia) and basil (O. sanctum) from middle portion of plant and dried fruits of gallnut (T. chebula) were collected. The leaves were dried under sun for a week, powdered in a mixer grinder and sieved through $0.25 \mathrm{~mm}$ sieve to obtain fine herbal powder. Similarly, gallnut fruit was separated as nut and mesocarp and the mesocarp alone were finely powdered in a mixer grinder and sieved through 0.25 mm sieve to obtain fine herbal powder.

The seeds of blackgram were coated with 5 per cent Carboxy methyl cellulose @ $200 \mathrm{ml}$ per kilogram of 
seed and then they were pelleted with leaf powders of noni and basil and fruit powder of gallnut @200 g per $\mathrm{kg}$ of seed and rolled for uniformity. The pelleted seeds were dried under shade for two days and were evaluated for following seed quality parameters.

Speed of germination: One hundred seeds of four replications were germinated in sand media as per the recommendations of International Seed Testing Association (ISTA), (2007) in germination room condition $\left(25^{\circ} \mathrm{C}\right.$ and $\left.95 \pm 2 \% \mathrm{RH}\right)$ along with unpelleted seed. Daily counts were taken in each of the treatment and replication upto the germination period of 7 days (ISTA, 2007) and speed of germination was calculated as per Maguire (1962).

Seed germination percentage: At the end of the germination period, the number of normal seedlings, were counted and expressed as seed germination per cent (ISTA (2007).

Shoot and root length: In each of the treatments and replications, ten seedlings were selected at random and measured for root length (the length between the collar region to the tip of primary root in centimeter) and shoot length (the shoot length from the collar region to tip of the true leaves in centimeter).

Dry matter production: The seedlings used for measuring shoot and root length were shade dried and then dried in a hot air oven at $80 \pm 2^{\circ} \mathrm{C}$ for $24 \mathrm{hrs}$ and cooled in desiccators containing calcium carbonate and weighed in milligram and reported as dry weight of 10 seedlings.

Seedling vigour index: Vigour index values were computed adopting the following formula given by AbdulBaki and Anderson (1973) and the values were reported as whole number without unit.

Seedling Vigour Index $=$ Seed germination $(\%) \times$ Total seedling length $(\mathrm{cm})$

Hardiness test: The pelleted seeds were evaluated for physical compactness created on the seed due to pelleting using hardiness tester as a measure of compactness that would interfere with emergence of seedling.

The pelleted seeds were also sown in raised bed nursery using 100 seeds of 4 replications and observed for speed of emergence as per Maguire (1962) and for field emergence based on normal seedling produced from the total seeds placed, at 10 days after sowing. The seedlings were also uprooted and were measured for root length, shoot length, dry matter production and vigour index as indicated above and were thinned @20 seedlings per replication and grown upto 30 days with regular watering. At 30 days, the leaves were measured for chlorophyll index using Soil Plant Analysis Development (SPAD) meter and were also counted for nodules per plant.

Statistical analysis: The data collected were statistically analyzed as per Panse and Sukhatme (1985) for understanding the significance at $\mathrm{P}=0.05$. The percentage values were converted to arcsine values before analysis. Non significant results were indicated as NS.

\section{RESULTS AND DISCUSSION}

The success of pelleting depends on the selection of filler material and the researchers recommend various organic and inorganic products for filling the seed (Lu et al., 1983; Khatun et al., 2011; Selvakumar et al., 2012 and Mathivanan et al., 2012). In the present investigation, the blackgram seeds pelleted with leaf powders of noni and basil (Fig. 1) recorded highly significant effect on seed germination and seedling vigour under laboratory condition. The seeds pelleted with basil recorded 6, 27, 8,4 and 23 per cent higher germination, root length, shoot length, dry matter production and vigour index compared to unpelleted seed, respectively. The influencive effect of basil leaf powder might be due to the nutrient value of the leaf powder which contains vitamin $\mathrm{C}$ and $\mathrm{A}$ and minerals like calcium, zinc and iron and many other phytonutrients (Anbarasu and Vijayalakshmi, 2007). The second best influencive effect was observed with noni leaf powder, which had improved germination by 2 per cent compared to unpelleted seed which might be due to the presence of amino acids and mineral nutrients as reported by Wang et al. (2002). But, the seeds pelleted with gall nut recorded 72 per cent lesser germination compared to unpelleted seed which might be due to the presence of inhibitory substances. Suryaprakash et al. (2012) reported that the gallnut fruit contain secondary metabolites such as Tannins, Chebulinic acid, Ellagic acid, Gallic acid, Punicalagin and Flavonoids. The inhibitory effect of any of these chemicals might have caused the failure of seed germination.

Lu et al. (1983) expressed that leaf powder contains saponins the precursor of gibberellins and micronutrients which could synergistically interact with amino acid, tryptophan to form the Indole Acetic Acid (IAA) that could invigourate the seed. Prasad (1994) opined that in botanical pelleting, the leaf powder acted as wick by absorbing/ regulating the soil moisture availability and thus enhanced better seed soil relationships, as indicated through higher seed and seedling quality characters of the pelleted seeds. Malarkodi (2003) opined that presence of macro and micro nutrients in the leaf powder as the cause for invigourative effect of botanical treatments. However, the seed pelleted with gallnut powder had the negative influence of seed pelleting with gallnut powder on seed germination and vigour might be due to the lethality of its chemical compound on seed quality which needs further investigation. The speed of germination was delayed in all the pelleting treatments which might be due to physical hindrance created by the filler material that restricts the radical emergence compared to unpelleted seed. This was confirmed with evaluation of the hardiness using hardiness tester. It was found that the hardiness of seed pelleted with gallnut, noni and basil were 27, 24 and 15 percent higher than unpelleted seed (Fig. 2). Similar delayed emergence with pelleted seed was also ex- 
Table 1. Influence of organic pelleting on field emergence and seedling quality characters of blackgram cv. ADT 3

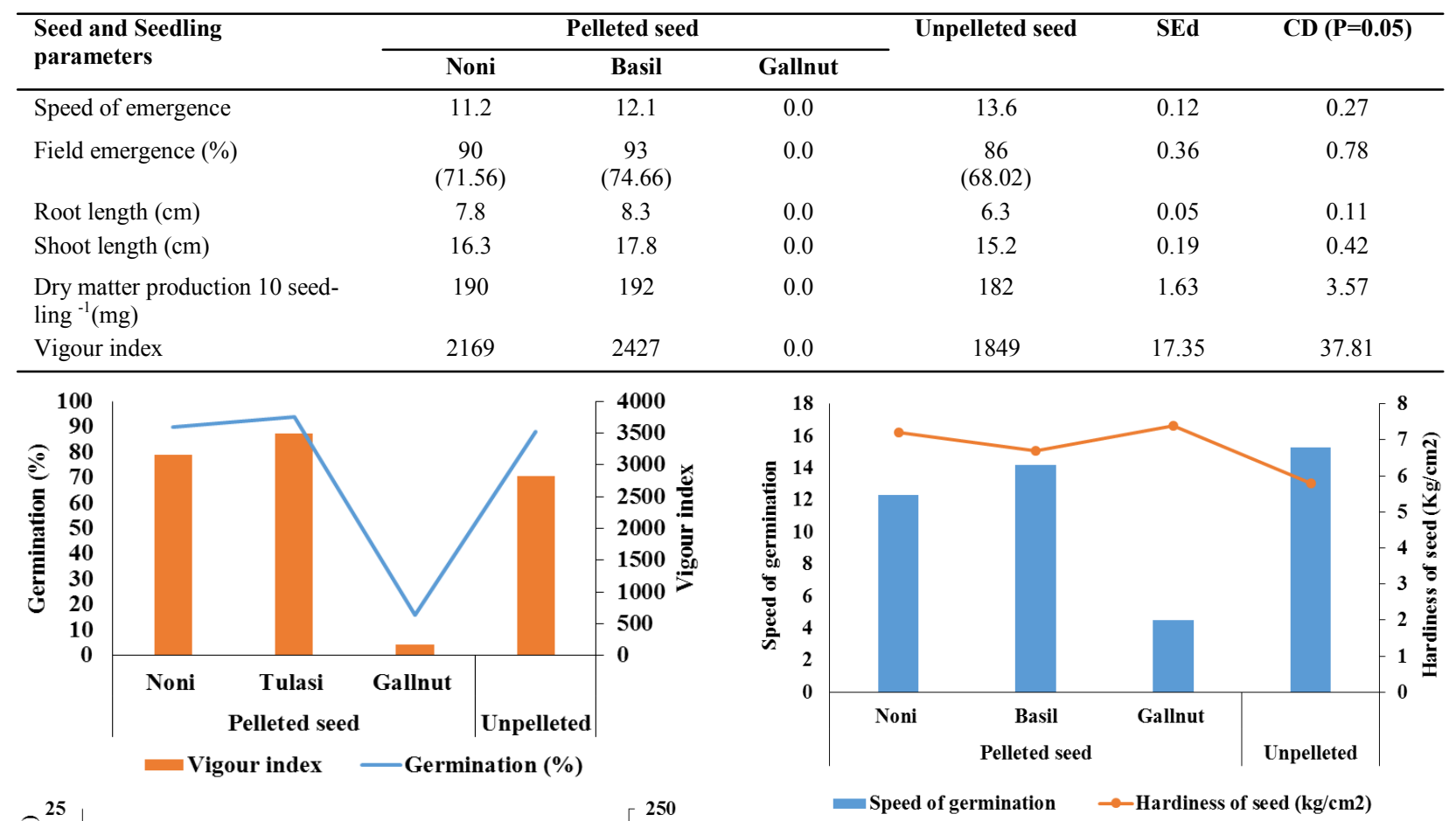

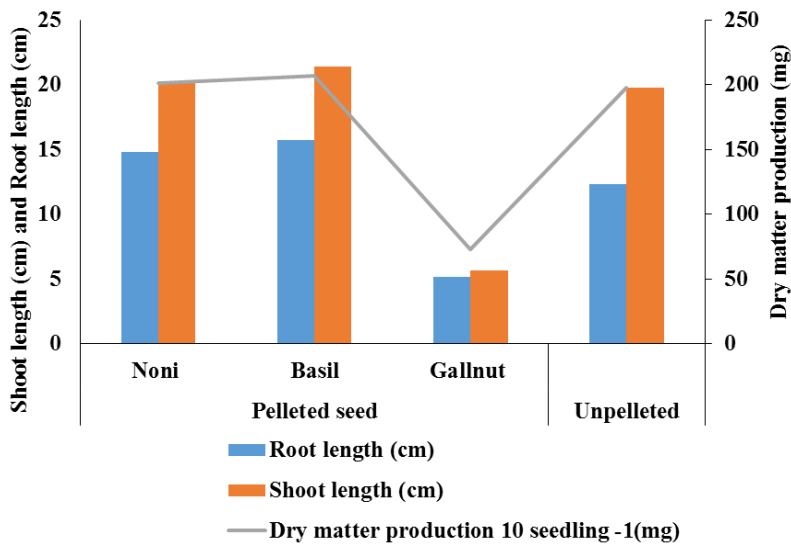

Fig. 1. Influence on seed pelleting with herbal powders on seed quality characters.

pressed (Barua (1994) in Acacia nilotica and Parameswari et al. (2001) in Tamarind) in different crops.

The evaluation of field emergence showed that seeds pelleted with basil excelled other herbal powders and registered 7 per cent higher field emergence compared to unpelleted seed, due to the easy dissolvable nature of the leaf powder that expressed through lesser hardiness in accordance with the results of laboratory test and it was followed by noni leaf powder while the performance of gallnut fruit powder had lesser seed quality characters than unpelleted seeds (Table 1). In addition, the leaf powders might have permitted an improvement in germination, emergence and improved the growth of plant which is favored in further stages too by way of improvement in plant height and better development of root system evaluated through root nodulation. The nodulation capacity of the filler material measured through the number of nodules (Fig. 3) indi-
Fig. 2. Influence of organic pelleting on speed of germination and hardiness of seed $\left(\mathrm{Kg} / \mathrm{cm}^{2}\right)$.

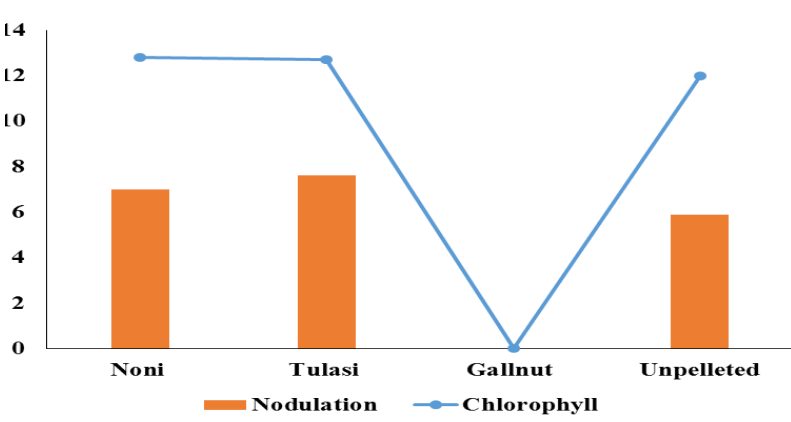

Fig. 3. Influence of organic pelleting on chlorophyll index and nodulation.

cated that nodule number recorded by basil and noni were 28 and 18 per cent higher than unpelleted seed.

The chlorophyll index observed in 30 days old seedling was highest with seeds pelleted with basil leaf powder and was followed by noni leaf powder and unpelleted seed, highlighting the cause for improved seedling vigour through improvement in the photosynthetic efficiency.

\section{Conclusion}

The study recommended seed pelleting with basil and noni leaf powder for improved seedling quality characters and field emergence. The improvement in field emergence and field establishment of pelleted seed was attributed to the improvement in chlorophyll index and enhanced nodule formation. The pelleted seed irrespective of filler material had delayed emergence due to hardiness of seed obtained by pelleting. However, the performance 
of seed pelleted with gallnut fruit powder had negative effect on seed and seedling quality characters.

\section{REFERENCES}

Abdul Baki, A. and Anderson, J.D. (1973). Vigour determination in soybean seed by multiple criteria. Crop Sci., 13: 630-633.

Anbarasu, K. and Vijayalakshmi, G. (2007). Improved shelf life of protein-rich tofu using Ocimum sanctum (tulsi) extracts to benefit Indian rural population. J. Food Sci., 72:300-305

Barua, R.S. (1994). Use of biofertilizers and its effect on seedlings growth. Indian Forester, 120 (4): 314-318.

Chandra, K. J. and D. D. G. Sagar. 2013. A review on the propagation methods of a miracle fruit morinda citrifolia L. Indian Journal of Plant Sciences, (2) 2: 78-84.

ISTA (2007). International Rules for Seed Testing: ISTA, Bassersdorf, Switzerland.

Kadian, R. and Parle, M. (2012). Therapeutic potential and phytopharmacology of tulsi. Int. J. Pharm. Life Sci., 3:1858-1867.

Khatun, A., Kabir, G., Bhuiyan, M.A.H. and Khanam, D. (2011). Effect of preserved seeds using different botanicals on seed quality of lentil. Bangladesh J. Agric. Res., $36(3): 381-387$.

Lu, S., Ming, D. and Jiang, T. (1983). A preliminary report on the effect of $\mathrm{CaCO}_{3}$ pelleted seeds of Chinese milk vetch on its yield. Shanghai Agric. Sci. and Technol., 6: 9170-9173.

Maguire, J.D. (1962). Speed of germination-aid in selection and evaluation for seedling emergence and vigour. Crop Sci., 2:176-177.

Malarkodi, K. (2003). Integrated management techniques for seed storage in greengram (Vigna radiate L. Wilczek). Ph.D. Thesis, Tamil Nadu Agricultural University, Coimbatore.

Mathivanan, S., Chidambaram, A., Sundaramoorthy. P. and
Kalaikandhan, R. (2012). Effect of vermicompost on germination and biochemical constituents of groundnut (Arachis hypogaea. L.) seedling. Int. J. of Res. in Biol. Sci., 2 (2): 54-59.

Panse, V.G. and Sukatme, P. V. (1985). Statistical methods for agricultural workers. ICAR publication, New Delhi, p. 359.

Parameswari, K., Srimathi, P. and Malarkodi, K. (2001). Infuence of biofertilizer pelletization on elite seedling production of tamarind (Tamarindus indica) in nursery. Seed Res., 29 (1): 58-62.

Prasad, K. N. (1994). Studies on certain aspects of seed management in soybean (Glycine $\max \mathrm{L}$ ) merill. Ph.D. thesis, TNAU, Coimbatore.

Selvakumar, G., Reetha, S. and Thamizhiniyan, P. (2012). Response of biofertilizers on growth, yield attributes and associated protein profiling changes of blackgram (Vigna mungo L. Hepper). World Appl. Sci. J., 16 (10): 1368-1374.

Shashibhaskar, M. S., Vinutha, K. S., Nagabhushan, S., Vasudevan, N. and Ramanjinappa, V. (2012). Seed quality as influenced by seed pelleting and containers during storage in tomato. Plant Archives, 12: 1101-1108.

Srimathi, P., Mariappan, N., Sundaramoorthy, L., and Paramathma. M. (2013). Effect of organic seed pelleting on seed storability and quality seedling production in biofuel tree species. Journal of horticulture and forestry, 5 (5): 68-73.

Suryaprakash, D. V., Sreesatya, N., Avanigadda, S. and Vangalapati, M. (2012). Pharmacological Review on Terminalia chebula. Int. J. of Res. In Phaarmaceutical and biomedical Sciences, 3 (2): 679-683.

Wang, M.Y., West, B. J., Jensen, C. J., Nowicki, D., Chen, S.U., Palu, A. and Anderson, G. (2002). Morinda citrifolia (Noni): A literature review and recent advances in noni research. Act a Pharmacol. Sin., 23 (12): 1127 -1141. 